\title{
Comparison of Quantitative Conformer Analyses by Nuclear Magnetic Resonance and Raman Optical Activity Spectra for Model Dipeptides
}

\author{
Miloš Buděšínský, ${ }^{\dagger}$ Petr Daněček, ${ }^{\dagger}$ Lucie Bednárová, ${ }^{\dagger}$ Josef Kapitán, ${ }^{\dagger}$ Vladimír Baumruk, ${ }^{\ddagger}$ and \\ Petr Bouř $*, \dagger$
}

Institute of Organic Chemistry and Biochemistry, Academy of Sciences, Flemingovo nám. 2, 16610, Prague 6, Czech Republic, and Charles University, Faculty of Mathematics and Physics, Institute of Physics, Ke Karlovu 5, 12116, Prague 2, Czech Republic

Received: July 13, 2008

\begin{abstract}
Interpretation of the Raman optical activity (ROA) of peptides is difficult because of molecular flexibility and interaction with the solvent. Typically, simulations and experiments are compared in terms of a qualitative agreement between the spectra. However, on a series of the Pro-Gly, Gly-Pro, Pro-Ala, and Ala-Pro dipeptides more precise conformer ratios could be obtained with the aid of the density functional computations and numerical decomposition of the spectral shapes. All observed transitions were assigned, and the computed transition frequencies were scaled accordingly. Then the populations predicted by the optical spectroscopy agreed within a few percent with an analysis of the spin-spin coupling constants based on the Karplus equations, which was confirmed also by a comparison of calculated and experimental NMR couplings. The results are supported by molecular dynamics simulations and related to the previous conformational studies of similar molecules.
\end{abstract}

\section{Introduction}

Since its discovery by Luis Pasteur in 1849, molecular optical activity has revolutionized crystallography ${ }^{1}$ and provided yet another powerful means to elucidate molecular structure, such as optical rotatory dispersion ${ }^{2}$ or ultraviolet circular dichroism. ${ }^{3}$ It was soon realized that even more detailed and more reliable stereochemical information can be obtained by extending this approach to the vibrational region where many more bands sensitive to molecular structure are resolved. ${ }^{4}$ Indeed, first observations of vibrational circular dichroism $(\mathrm{VCD})^{5}$ and Raman optical activity $(\mathrm{ROA})^{6}$ were quickly followed by numerous applications in organic chemistry and molecular biology, ranging from small chiral molecules to proteins, nucleic acids, and viruses. ${ }^{7}$

The ROA combines the increased structural sensitivity of the polarized methods with the broad range of frequencies enabled by the laser light. It is particularly suitable for studies of biologically relevant molecules in their natural (aqueous) environment. ${ }^{8-10}$ A reliable interpretation of the spectra, however, is almost entirely dependent on lengthy and inherently approximate quantum-chemical computations. For nonpolar systems the theoretical analysis provided astonishing details about molecular structure. ${ }^{11}$ On the other hand, flexible and polar molecules are particularly difficult to model. ${ }^{9,10,12-15}$ However, a detailed spectral analysis as outlined in the present paper yields conformer ratios of model dipeptides that fit benchmark NMR data very well indeed.

For the analysis we chose ROA spectra of the Pro-Gly, GlyPro, Pro-Ala, and Ala-Pro dipeptides as they indicate interesting differences in flexibility of these compounds. ${ }^{9}$ The presence of the proline ring additionally provides an opportunity to study

* To whom correspondence should be addressed. E-mail: bour@ uochb.cas.cz.

$\dagger$ Academy of Sciences.

$\ddagger$ Charles University. conformation of a peptide side chain often undetectable by other spectroscopic techniques. The polarizable ring is invisible, for example, in $\mathrm{VCD},{ }^{16}$ but provides a strong ROA signal. ${ }^{10,13}$ Accurate density functional theory (DFT) ${ }^{17}$ simulations with a polarized continuum solvent model ${ }^{18}$ enabled us to compare the experimental spectra with calculated frequencies and intensities. Instead of the usual comparison of the simulated and experimental shapes, however, we use a statistical decomposition based on the best overlap. ${ }^{19}$ With a correct assignment and scaling of the calculated intensities, the decomposition limits observer's bias in interpreting the spectra and provides more accurate estimates of the conformer ratios.

\section{Method}

Experimental. Backscattered Raman and incident circular polarization (ICP) ROA spectra of four commercial dipeptides (Figure 1) were recorded on a spectrometer located at the Charles University (Prague) described elsewhere. ${ }^{14,20}$ The samples consisted of Gly-Pro (2 M), Pro-Gly (0.89 M), AlaPro (1.33 M), and Pro-Ala (0.23 M) aqueous solutions, and their raw Raman and ROA spectra and full experimental details can be found in the literature. ${ }^{9}$ The IR spectra (about $10 \%(\mathrm{w} / \mathrm{w})$ aqueous solutions, i.e. $0.53 \mathrm{M}$ for Pro-Ala and Ala-Pro, and $0.58 \mathrm{M}$ for Gly-Pro and Pro-Gly) were acquired on a Vectra 33 FTIR spectrometer (Bruker) using a single reflection diamond HATR accessory (Pike Technologies). The ATR compartment was chosen because it allowed for a wide frequency range and without the interference observed in the usual transmission IR setup. The IR spectra can be found in the Supporting Information and were used for an additional control of the transition assignments. The ${ }^{1} \mathrm{H}$ and ${ }^{13} \mathrm{C}$ NMR spectra of all four peptides were measured on a Bruker AVANCE 600 instrument $\left({ }^{1} \mathrm{H}\right.$ at $600.13 \mathrm{MHz} ;{ }^{13} \mathrm{C}$ at $150.92 \mathrm{MHz}$ ) in $\mathrm{D}_{2} \mathrm{O}$ with dioxane as internal reference $\left(\sigma_{\mathrm{H}}=3.75 ; \sigma_{\mathrm{C}}=69.3\right)$ at three temperatures $(278,300$, and $322 \mathrm{~K})$. 


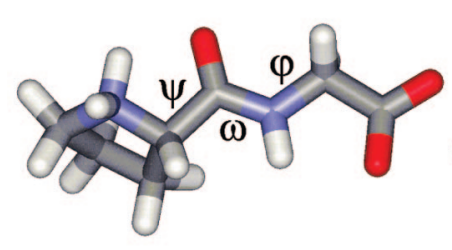

Pro-Gly

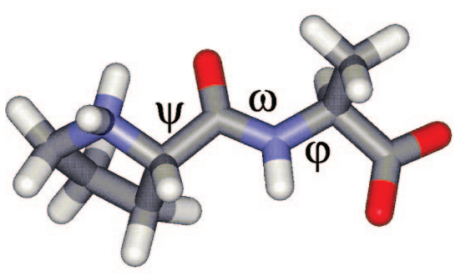

Pro-Ala

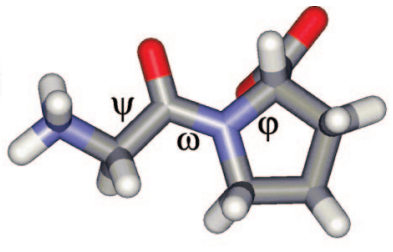

Gly-Pro

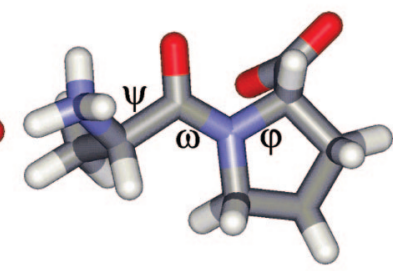

Ala-Pro
Figure 1. Lowest-energy conformers of the four dipeptides obtained at the B3LYP/6-31++G**/CPCM level. The main chain torsion angles are defined as: $\psi=\angle\left(\mathrm{N}-\mathrm{C}_{\alpha}-\mathrm{C}^{\prime}-\mathrm{N}\right), \omega=\angle\left(\mathrm{C}_{\alpha}-\mathrm{C}^{\prime}-\mathrm{N}-\mathrm{C}_{\alpha}\right)$ and $\varphi=\angle\left(\mathrm{C}^{\prime}-\mathrm{N}-\mathrm{C}_{\alpha}-\mathrm{C}^{\prime}\right)$.

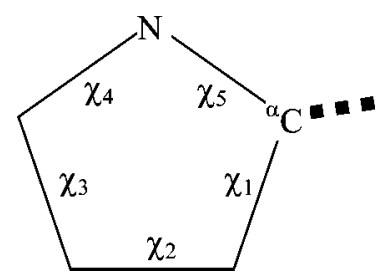

$$
\begin{gathered}
\tan (P)=\frac{\chi_{1}+\chi_{4}-\chi_{3}-\chi_{5}}{2 \chi_{2}[\sin (\pi / 5)+\sin (2 \pi / 5)]} \\
\chi_{m}=\chi_{2} / \cos (P)
\end{gathered}
$$

Figure 2. Definition of the torsion angles $\chi_{1-5}$ and the puckering phase $(P)$ and amplitude in the L-proline ring.

The NMR spectra (recorded at 278, 300, and $322 \mathrm{~K}$ ) showed practically no temperature dependence of chemical shifts $\left({ }^{1} \mathrm{H}\right.$ and $\left.{ }^{13} \mathrm{C}\right)$ and coupling constants $(J(\mathrm{H}, \mathrm{H}))$ for all four peptides. Their NMR parameters measured at $300 \mathrm{~K}$ are summarized in Tables S1-S4 of the Supporting Information. For dipeptides Gly-Pro and Ala-Pro a small increase of population in Pro isomers with cis-amide bond was observed with rising temperature. The two-state model was adopted for the calculation of proline ring geometry and equilibrium population from vicinal spin-spin coupling constants $(J(\mathrm{H}, \mathrm{H})) .^{21}$

Computations. Gaussian ${ }^{22}$ software was used for geometry optimization and simulation within the harmonic approximation of Raman and ROA intensities. Anharmonic corrections for the Pro-Ala molecule were calculated according to the methods described in the literature, ${ }^{23}$ but these did not lead to a convincing improvement and are not used in the conformer analysis. A systematic scan over the main chain torsion angles $(\omega, \varphi, \psi$, see Figure 1) revealed the lowest-energy conformers, equilibrium geometries of which were optimized by energyminimization at the $\mathrm{B} 3 \mathrm{LYP}^{24} / 6-31++\mathrm{G}^{* *}$ level using the CPCM Gaussian version of the COSMO $^{25,26}$ solvent model for water. For cis-forms of Ala-Pro the $(\mathrm{C}) \mathrm{O} \cdots(\mathrm{N})$ distance was kept fixed at $1.8 \AA$ in order to account for the inaccuracy of the CPCM model that provided the distance to be too short with unrealistic vibrational frequency of the $\mathrm{N}-\mathrm{H}$ stretching mode. A lower B3LYP/6-31G*/CPCM level was used for a preliminary conformer search. The ring puckering is described by the pseudorotation phase and amplitude ${ }^{13,27,28}$ defined in Figure 2.

To verify the ab initio structures and to obtain estimates of the equilibrium torsion angle dispersions, the dipeptides were explored with the Tinker molecular dynamics (MD) package. ${ }^{29}$
Each molecule was placed in a periodic cubic box (18.6 ̊̊ wide) filled with water and after minimization MD was monitored for $1 \mathrm{~ns}$ (the simulation was run with standard Tinker parameters for NpT ensemble, i.e. 1 fs integration steps, temperature 298 $\mathrm{K}$, and pressure $1 \mathrm{~atm}$ ). The standard Amber99 ${ }^{30}$ (all peptides) and polarizable Amoeba ${ }^{31,32}$ (for Ala-Pro only) force fields were applied and the torsion angle distribution analyzed by our program scripts.

For optimized geometries, the Raman intensities and vibrational frequencies were obtained at the same B3LYP/6 $-31++\mathrm{G}^{* *} /$ CPCM level, while HF/6-31G/CPCM and B3LYP/6-31G**/ CPCM levels (without further geometry optimization) were used for the computationally more demanding ROA intensity tensors. ${ }^{33}$ The Cartesian tensor transfer techniques ${ }^{34}$ and the tensor origin dependence ${ }^{35}$ were exploited for a standard combination of the Raman and ROA tensors calculated at different levels. ${ }^{36}$ Respective back-scattering Raman and ROA intensities were obtained for each mode from ${ }^{37,38}$

$$
I_{\text {Ram }}=6 \sum_{i=1 . .3, j=1 . .3}\left(7 \alpha_{i j} \alpha_{i j}+\alpha_{i i} \alpha_{i i}\right)
$$

and

$$
\begin{aligned}
& I_{\mathrm{ROA}}= \\
& \quad \frac{48}{c} \sum_{i=1 . .3, j=1 . .3}\left(3 \alpha_{i j} G_{i j}^{\prime}-\alpha_{i i} G_{j j}^{\prime}+\omega_{\mathrm{exc}} \sum_{k=1 . .3} \varepsilon_{i j k} \alpha_{i l} A_{j k l} l 3\right)
\end{aligned}
$$

where $\alpha, \mathbf{G}^{\prime}$, and $\boldsymbol{A}$ are the corresponding polarizability, optical rotation tensor, and dipole-quadrupole polarizability derivatives, ${ }^{33}$ respectively, $c$ is the in vacuo light velocity. From the intensities Lorentzian spectral shapes were generated from individual peaks as

$$
S(\omega)=I_{\text {RamROA }}\left[1-\exp \left(-\frac{\omega_{i}}{k T}\right)\right]^{-1} \frac{1}{\omega_{i}}\left[4\left(\frac{\omega-\omega_{i}}{\Delta}\right)^{2}+1\right]^{-1}
$$

where $\left(\omega_{i}\right) \omega$ is the (normal mode) angular frequency, $k$ is the Boltzmann constant, $T$ is the temperature, and $\Delta$ is the full width of the Lorentzian peak measured at half-maximum. As the absolute intensities are rarely measured, computed spectra were adjusted by one scale factor (common to Raman and ROA) to the average experimental intensity.

Spectral Analysis. Using the recently developed algorithm, ${ }^{19}$ normalized experimental Raman and ROA spectra $S_{\mathrm{e}}$ were decomposed into the theoretical curves $s_{i}$,

$$
S_{\mathrm{e}}=\sum_{i=1 . . m} b_{i} s_{i}
$$

where the sum runs over all conformers and $\sum_{i=1 . . m} b_{i}=1$. The ratios $b_{i}$ were obtained by minimization of the sum $\sum_{j}$ $\left(S_{\mathrm{e}}\left(\omega_{j}\right)-\sum_{i=1 . . m} b_{i} s_{i}\left(\omega_{j}\right)\right)^{2}+\alpha \sum_{i=1 . . m}\left(b_{i}-1 / m\right)^{2}$, where spectral intensities within $\omega \in\left(300 . .0 .1800 \mathrm{~cm}^{-1}\right)$ were included. The penalty function (last term, with $\alpha=0.02$ and $\alpha=0.2$, for Raman and ROA, respectively) prevented the coefficients $b_{i}$ from becoming too negative.

In addition to the raw ab initio results, scaled force constants $\mathbf{F}^{\prime}=\mathbf{S}^{t} \boldsymbol{\Omega} \mathbf{S}$ were used for the spectra generation with the Cartesian-normal mode transformation matrix $\mathbf{S}$ obtained from the DFT force field. The diagonal matrix $\boldsymbol{\Omega}$ contained the experimental frequencies acquired by analysis of the ROA, Raman, and IR spectra which are summarized in Tables S5-S8 of Supporting Information. 
TABLE 1: Relative Energies (E) and Geometry Parameters of the Dipeptide Conformers Obtained at the B3LYP/ 6-31++G**/CPCM level, and the NMR-Derived Puckering Coordinates

$\begin{array}{llllllll}E & \psi & \varphi & \omega & P & \chi_{\mathrm{m}} & P_{\mathrm{NMR}} & \chi_{\mathrm{mNMR}}\end{array}$ conformer (kcal/mol) (deg) (deg) (deg) (deg) (deg) (deg) (deg)

\begin{tabular}{llrrrrrrr}
\hline $\begin{array}{l}\text { Pro-Gly } \\
\text { n }\end{array}$ & 0.0 & 162 & 178 & 177 & 9 & 41 & 3 & 43 \\
s & 0.3 & 162 & 178 & 176 & 210 & 40 & 216 & 42 \\
Gly-Pro & & & & & & & & \\
tn & 0.9 & -178 & -63 & 178 & 19 & 38 & 15 & 44 \\
ts & 0.8 & 171 & -76 & 178 & 169 & 38 & 189 & 39 \\
cn & 0.2 & -158 & -58 & -2 & 15 & 38 & 16 & 41 \\
cs & 0.0 & -176 & -73 & -2 & 170 & 39 & 180 & 40 \\
Pro-Ala & & & & & & & & \\
n & 0.0 & 161 & -155 & 176 & 4 & 41 & 4 & 41 \\
s & 0.3 & 161 & -155 & 175 & 212 & 40 & 216 & 40 \\
Ala-Pro & & & & & & & & \\
tn & 4.2 & 151 & -62 & 176 & 20 & 38 & 5 & 43 \\
ts & 4 & 151 & -78 & 179 & 172 & 38 & 199 & 42 \\
cn & 0.0 & 106 & -55 & -12 & 19 & 38 & 23 & 43 \\
cs & 0.5 & 86 & -83 & 5 & 166 & 40 & 180 & 41 \\
Ala-Ala ${ }^{43}$ & - & 147 & -153 & 172 & - & - & - & -
\end{tabular}

NMR chemical shifts and spin-spin couplings $\left(J_{\text {cal }}\right)$ were calculated by Gaussian at the B3LYP/6-311++G**/ $\operatorname{PCM}\left(\mathrm{H}_{2} \mathrm{O}\right)$ level for all equilibrium structures, using the GIAO default option. Alternatively to the standard empirical analysis ${ }^{21}$ the experimental coupling constants $\left(J_{\text {exp }}\right)$ were directly compared to the calculation and the proline ring conformer ratio of the north-conformer $b_{n}$ was also obtained from a two-state model fit as

$$
b_{n}=\frac{\sum_{k}\left(J_{\mathrm{cal}, s, k}-J_{\text {exp }, k}\right)\left(J_{\text {cal }, s, k}-J_{\text {cal }, n, k}\right)}{\sum_{k}\left(J_{\text {cal }, s, k}-J_{\text {cal }, n, k}\right)^{2}}
$$

where the index $k$ runs over the experimentally available values. Note that $b_{n}+b_{s}=1$.

\section{Results and Discussion}

Dipeptide Conformers. Calculated relative energies and the principal geometry parameters of all equilibrium structures listed in Table 1 are consistent with the NMR data. In accord with the previous observations ${ }^{10,13,39,40}$ the proline ring is predicted to adopt two approximately equally populated conformers, differing in energy less than by $\sim 0.5 \mathrm{kcal} / \mathrm{mol}$, referred to as $\mathrm{n}$ ("north", $P \sim 0^{\circ}$ see Figure 2) and s ("south", $P \sim 180^{\circ}$ ). We can approximately imagine these conformers as envelopes where the tip opposite to the $\mathrm{C}-\mathrm{N}$ main chain bond is tilted above and under the plane $\left(\chi_{5} \sim 0\right.$, Figure 2$)$. The error bars for the experimental proline puckering amplitudes and phases obtained by the spin-spin coupling constant analysis ${ }^{21}$ were determined as $2-3^{\circ}$, and the angular values depended on the choice of the fitting parameters somewhat more then the final conformer ratios. The DFT-predicted phases and puckering amplitudes are thus in an excellent agreement with those obtained by NMR. For Gly-Pro and Ala-Pro, additionally both the cis (c) and trans (t) isomers can coexist at room temperature due to the presence of the tertiary amide group, providing thus in total four ts, tn, cs, and cn conformers (Figure 3).

The differences in the peptide main chain conformation are clearly caused by the side chains, e.g. $\varphi$-variance between ProGly and Pro-Ala can be attributed to the repulsion between the methyl group and the proline residue. For the peptides with

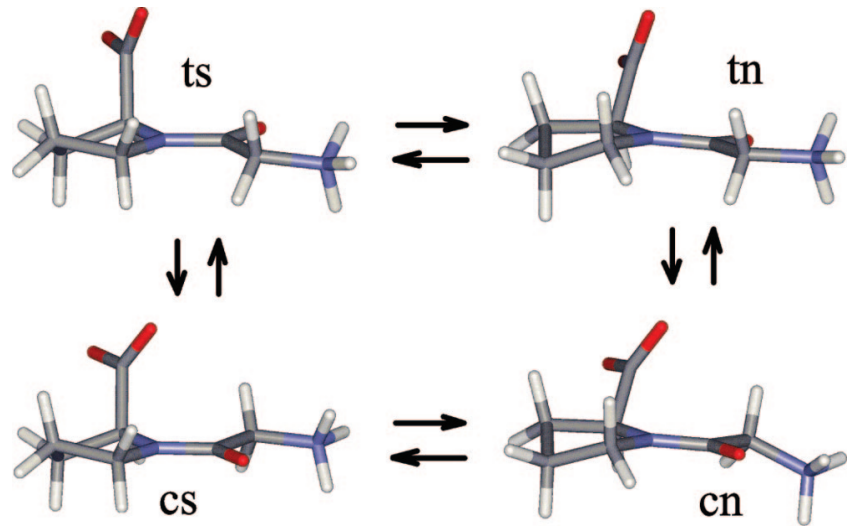

Figure 3. The four lowest-energy conformers of Gly-Pro obtained as equilibrium geometries at the $\mathrm{B} 3 \mathrm{LYP} / 6-31++\mathrm{G} * * / \mathrm{CPCM}$ potential energy surface. The first letter refers to the trans-cis isomerization, while the second to the south-north pseudorotation of the puckered proline ring.

TABLE 2: Temperature Dependence of trans- and cis-X-Pro NMR Experimental Ratios in $\mathrm{D}_{2} \mathrm{O}$ and the Related Experimental Entropy $(\Delta S)$ and Enthalpy Changes $(\Delta H)$ for the $\mathrm{Cis} \rightarrow$ Trans Isomerization

\begin{tabular}{|c|c|c|c|c|c|}
\hline & ratio & trans:cis & omers & & \\
\hline compound & $T=278$ & $T=300$ & $T=322 \mathrm{H}$ & $1 / \mathrm{mo}$ & $\mathrm{cal} / \mathrm{m}$ \\
\hline Gly-Pro & $61.1: 38.9$ & $59.8: 40.2$ & $58.6: 41.4$ & 0.62 & 0.80 \\
\hline Ala-Pro & $60.2: 39.8$ & $58.9: 41.1$ & $57.5: 42.5$ & 0.42 & 0.40 \\
\hline
\end{tabular}

the proline at the right-hand side (Gly-Pro, Ala-Pro), it is the $\psi$-angle that is changed most by the presence of the alanine methyl group in comparison with the glycine. Thus, the finetuning of the peptide conformational properties by the side chain important for the peptide folding ${ }^{41}$ can be already followed on the simple models. The similarity between the Pro-Ala and AlaAla equilibrium conformations supports the original idea ${ }^{9}$ about a minor effect of the proline residue attached on the peptide $\mathrm{N}$-end on the main chain conformation.

The low relative conformer energies suggest that many conformers are present in the samples at room temperature, although the computed values might not be too accurate because of the limitations of the DFT method and the internal hydrogen bonds not well-described by the continuum solvent model. ${ }^{42,43}$ Indeed, the enthalpies corresponding to the cis-trans isomerization extracted from the NMR data (Table 2) are well below the computational error. ${ }^{19}$

The DFT-predicted equilibrium geometries are in a reasonable agreement with the average angles found by the molecular dynamics (MD) computations. The MD angular distributions (Figure 4) for the Pro-Gly and Pro-Ala peptides exhibit similar $\psi$ and $\varphi$ main chain torsion angles properties as in the Ala-Ala molecule ${ }^{43}$ which again suggests a limited influence of the side chains on the backbone conformation in this case. The computationally more demanding Amoeba force field was attempted only for the Ala-Pro peptide (bottom of Figure 4); in this case it produced average geometries and dispersion very similar to that obtained by the Amber force field. Detailed conformer distributions differ most in the proline puckering of the trans isomer, where Amoeba strongly favors the south conformer. The polarizable force field also favors a broader $\psi$-distribution for the trans isomer and, perhaps surprisingly, broader and an asymmetric $\omega$-distribution in the cis isomer. The polarization effects thus mediate the chirality induced in the amide group by the amino acid side chains. Interestingly, a significantly larger 
Amber99 Force Field:
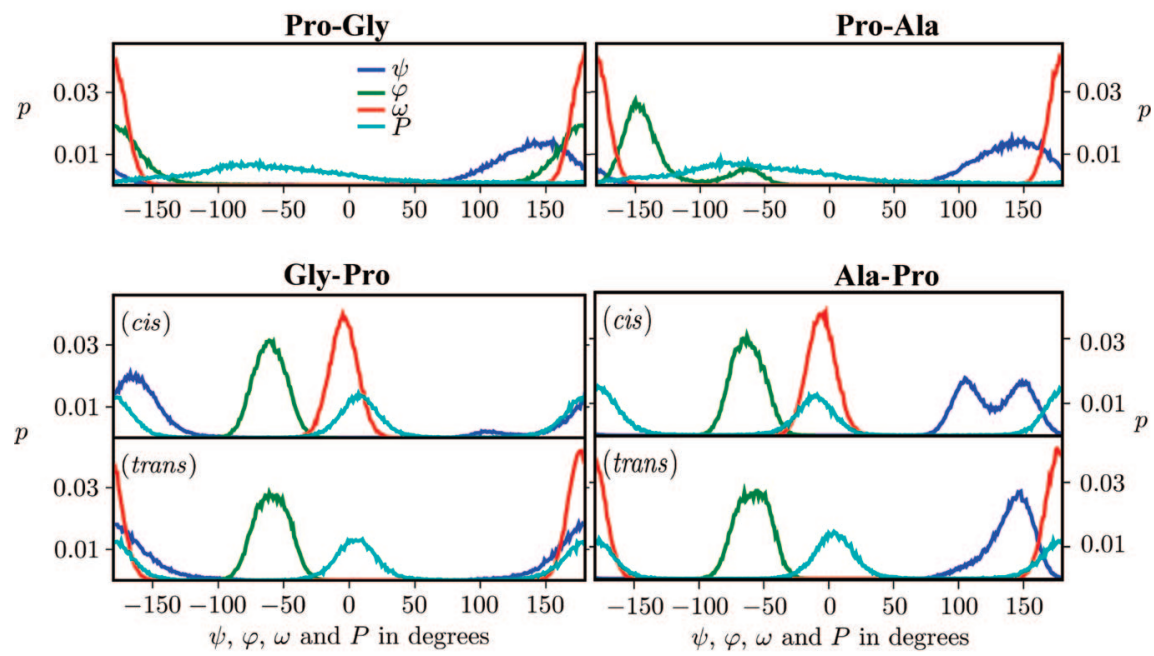

\section{Amoeba Force Field:}

Ala-Pro

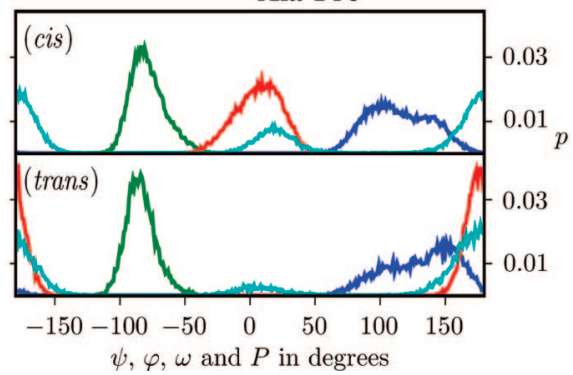

Figure 4. Probability distributions of the $\psi, \varphi, \omega$ angles and the proline puckering $P$ (plotted by the blue, green, red, and aqua curves, respectively) in the four dipeptides obtained by molecular dynamics.
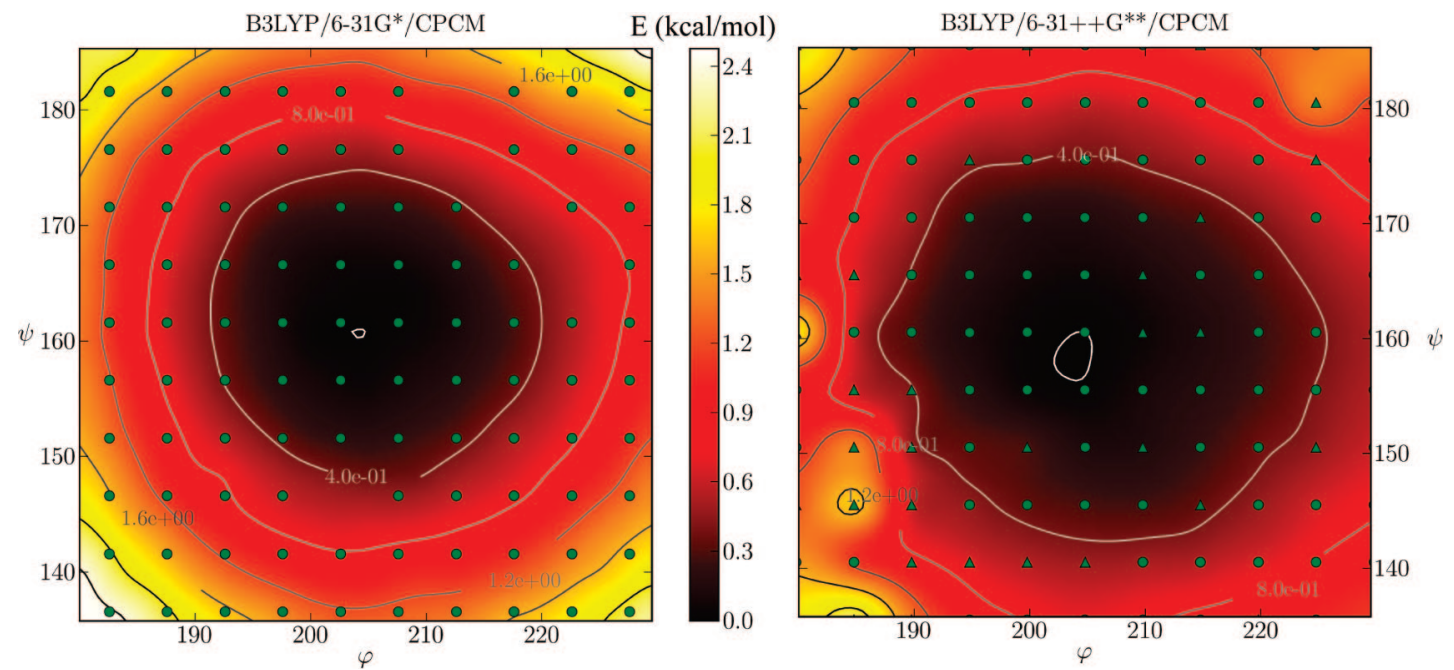

Figure 5. Ab initio potential energy surface of the Pro-Ala molecule computed at two approximation levels. Although the equilibrium geometries $\left(\varphi \sim 205^{\circ}, \psi \sim 160^{\circ}\right)$ are similar, the potential in the bigger basis is flatter in the vicinity of the minimum.

flexibility for the proline puckering in Pro-Gly and Pro-Ala is predicted by MD than by the current and previous DFT modeling ${ }^{10}$ which can be most probably attributed to the limited accuracy of the MD force fields. ${ }^{44}$ Additionally, the pseudorotation puckering coordinates might not be quite adequate for a detailed description of the proline behavior as the individual torsional angles exhibit sharper MD distributions. ${ }^{45}$

The MD angular dispersions also approximately copy the Boltzman probabilities obtained from the ab initio potential energy surfaces plotted for Pro-Ala in Figure 5 as calculated at the B3LYP/6-31G**/CPCM and B3LYP/6-31++G**/CPCM levels. The flatness of the DFT surface is somewhat modulated by the basis set size, which confirms the importance of the diffusion functions for a proper description of the polar and charged molecules. However, the continuum solvent model may not be adequate for an accurate description of the peptide conformational behavior because of the lack of the explicit directional hydrogen bonds. ${ }^{10,12-15}$ 


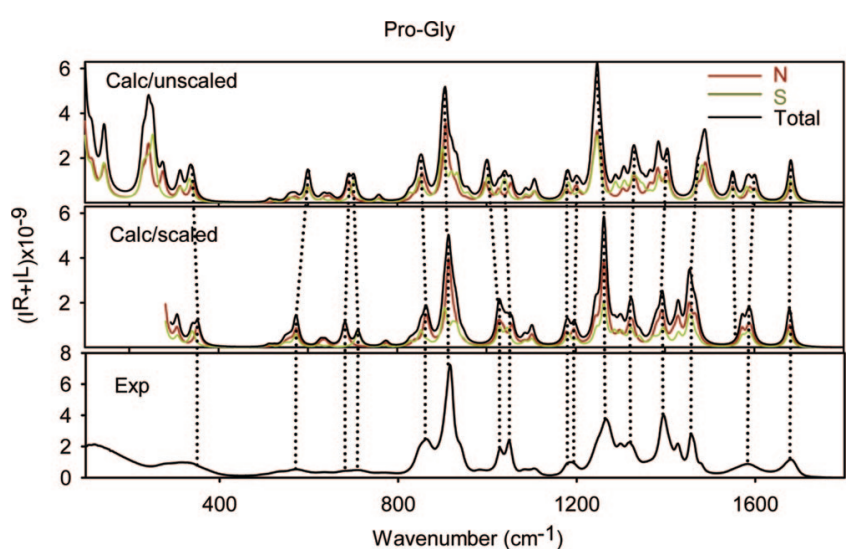

Figure 6. Example of the spectral decomposition and frequency scaling for the Raman spectra of Pro-Gly. The unscaled (B3LYP/6-31++G**/ CPCM, top) and scaled (scaled frequencies can be found in Table S2 of Supporting Information, middle) are compared to the experiment (bottom), selected corresponding frequencies are connected by the dotted lines, the decomposition to the north and south conformers (Table 3 ) is indicated in the theoretical spectra.

Vibrational Transitions. Finally, we can decompose the experimental spectra into the scaled simulated curves for the equilibrium conformers according to eq 4 . An example of the decomposition for the unscaled and scaled frequencies is presented in Figure 6, where the calculated Raman spectra for the Pro-Gly dipeptide are compared to the experiment. We can see that most of the observed vibrational bands can be assigned relatively easily (and the assignment can also be checked by a similar comparison of the ROA and IR intensities, not shown). However, smaller or larger adjustments are needed throughout the entire range of frequencies. Within $\sim 1200-1500 \mathrm{~cm}^{-1}$ the assignment is somewhat problematic because of the many overlapping bands (belonging mainly to the $\mathrm{C}-\mathrm{H}$ bending vibrations). Therefore, frequencies of the transitions that could not be identified in the experiment were interpolated according to the neighboring more characteristic bands, so that the calculated frequency order was not changed. It is generally accepted that the computed frequency ordering is reliable; for the conformer weights an occasional switch would cause a relatively minor error because of the averaging of many bands within the entire region.

A complete assignment of the observed transitions in the Raman and ROA spectra indicated in Figure 7 is listed in Tables S5-S8 of Supporting Information. For all the compounds the Raman and ROA intensities are dominated by similar vibrational modes, such as the proline-ring deformation (around $550 \mathrm{~cm}^{-1}$ ), amide $\mathrm{CO}$ and $\mathrm{CO}_{2}$ out of plane deviation (at $\sim 780 \mathrm{~cm}^{-1}$ ), proline breathing and other single-bond stretching modes (860-917 $\mathrm{cm}^{-1}$ ), an amide signal at $\sim 1045 \mathrm{~cm}^{-1}$, $\mathrm{CH}$ and $\mathrm{CH}_{2}$ bending twist $\left(\sim 1300 \mathrm{~cm}^{-1}\right)$ and scissoring $\left(\sim 1450 \mathrm{~cm}^{-1}\right)$, and a broad signal of the polar $\mathrm{NH}_{x}$ (scissoring), $\mathrm{CO}_{2}$ (locally asymmetric stretch $)$, and $\mathrm{CO}(\mathrm{C}=\mathrm{O}$ stretch, amide $\mathrm{I})$ groups $\left(1610-1680 \mathrm{~cm}^{-1}\right)$. Detailed mode ordering is dependent on a chemical species and particular conformation that provide distinct spectral patterns for the four dipeptides.

The signal below $\sim 280 \mathrm{~cm}^{-1}$ is obscured by the coupling of the peptide and water vibrations. ${ }^{13}$ The region below $\sim 800 \mathrm{~cm}^{-1}$ is severely affected by flexibility of the molecules, such as rotation of the functional $\mathrm{NH}_{3}, \mathrm{CH}_{3}$, and $\mathrm{CO}_{2}$ groups, ${ }^{9}$ and perhaps also by oscillations of the backbone parameters (Figure 4). Within the range of $\sim 1550-1700 \mathrm{~cm}^{-1}$ the signal is considerably broadened by an interaction of the polar $\mathrm{NH}_{x}{ }^{+}$and $\mathrm{CO}^{2-}$ groups with the solvent. As a result the ROA signal
TABLE 3: Conformer Populations (\%) of the Dipeptides Determined from B3LYP/6-31++G**/CPCM Energies and Analyses of the NMR, Raman, and ROA Spectra

\begin{tabular}{|c|c|c|c|c|c|c|c|c|}
\hline & calcd & $\mathrm{NMR}^{a}$ & $\mathrm{NMR}^{b}$ & $\begin{array}{c}\text { Raman, } \\
\text { b31 }\end{array}$ & $\begin{array}{c}\text { Raman, } \\
\text { b31/sc }\end{array}$ & $\begin{array}{c}\text { ROA, } \\
\text { HF }\end{array}$ & $\begin{array}{c}\text { ROA, } \\
\text { b31 }\end{array}$ & $\begin{array}{l}\text { ROA, } \\
\text { b31/sc }\end{array}$ \\
\hline \multicolumn{9}{|l|}{ Pro-Gly } \\
\hline $\mathrm{n}$ & 62 & 50 & 53 & 40 & 54 & 49 & 40 & $\begin{array}{l}51 \\
48\end{array}$ \\
\hline $\begin{array}{l}\text { S } \\
\text { Gly-Pro }\end{array}$ & 38 & 50 & 47 & 60 & 45 & 51 & 60 & 48 \\
\hline \multicolumn{9}{|l|}{ Gly-Pro } \\
\hline tn & 10 & 19 & 19 & 24 & 24 & 10 & 19 & 11 \\
\hline ts & 13 & 41 & 41 & 26 & 36 & 40 & 43 & 47 \\
\hline $\mathrm{cn}$ & 33 & 10 & 10 & 14 & 9 & 25 & 10 & 12 \\
\hline cs & 44 & 30 & 30 & 35 & 32 & 25 & 28 & 30 \\
\hline \multicolumn{9}{|l|}{ Pro-Ala } \\
\hline $\mathrm{n}$ & 60 & 54 & 55 & 34 & 43 & 47 & 51 & 58 \\
\hline s & 0 & 46 & 45 & 66 & 57 & 53 & 49 & 42 \\
\hline \multicolumn{9}{|l|}{ Ala-Pro } \\
\hline tn & 0 & 27 & 28 & 12 & 15 & 38 & 32 & 31 \\
\hline ts & 0 & 32 & 32 & 34 & 41 & 39 & 43 & 36 \\
\hline $\mathrm{cn}$ & 30 & 9 & 9 & 34 & 16 & 5 & 3 & 7 \\
\hline cs & 70 & 32 & 31 & 20 & 35 & 18 & 20 & 25 \\
\hline$\delta$ & 14 & 0 & 1 & 10 & 5 & 6 & 5 & 3 \\
\hline
\end{tabular}

${ }^{a}$ Empirical analysis. ${ }^{21}{ }^{b}$ Semiempirical analysis, eq 5. $\delta$-Average absolute deviation from the NMR values. b31 and b31/sc refer to the decomposition of the experimental spectra to the B3LYP unscaled and scaled simulations (eq 4). The $6-31++\mathrm{G}^{* *}$ basis and the CPCM solvent model were used for all the Raman/ROA computations.

becomes very weak in these regions. Overall, the simulated spectra with scaled frequencies faithfully reproduce the Raman intensity patterns, within the limits set by experimental noise and artifacts, ${ }^{12}$ the limited accuracy of DFT and harmonic methods. ${ }^{23}$ For ROA, although most of the bands could be assigned on the basis of the combined information from the Raman, IR, and ROA spectra, the intensity agreement is not so good, especially at regions where the signal is broadened and the water scattering high, or when many frequency-close overlapping transitions occur. Nevertheless, the main spectral features and the strongest ROA signal within $\sim 700-1600 \mathrm{~cm}^{-1}$ are reproduced well, i.e. the calculations provide correct relative intensities and signs.

Most probably, the weak signal of many ROA bands in ProAla, and partially also for Pro-Gly, is caused by the flexibility of the proline ring, indicated also by the MD simulations (Figure 4). Additionally, the experimental Pro-Ala spectrum exhibits the largest noise, which may be given by sample fluorescence, impurities, or other factors beyond our control. Still, because of the good agreement between the simulated and experimental Raman spectra, and a good reproduction of the most important ROA spectral features, we consider the two (four)-conformer model (Figure 3) appropriate.

Indeed, in spite of the experimental noise and the limited precision of the computations, the decomposition of the experimental intensities into simulated spectra provides accurate conformer populations (Table 3). In particular, the ratios obtained from the scaled ROA spectra (last column of Table 3, Figure 8) virtually follow the NMR data. The scaling (or, ideally, exact computation of the frequencies) thus appears necessary for the correct decomposition; otherwise intensities of different transitions might be compared. The experimental error associated with the empirical and ab initio NMR analyses is estimated as $\sim 3 \%$. Also the agreement between the NMR populations obtained with the empirical and computed spin-spin coupling parameters (third and fourth columns of Table 3 ) confirms the reliability of the NMR-determined populations. Although the 


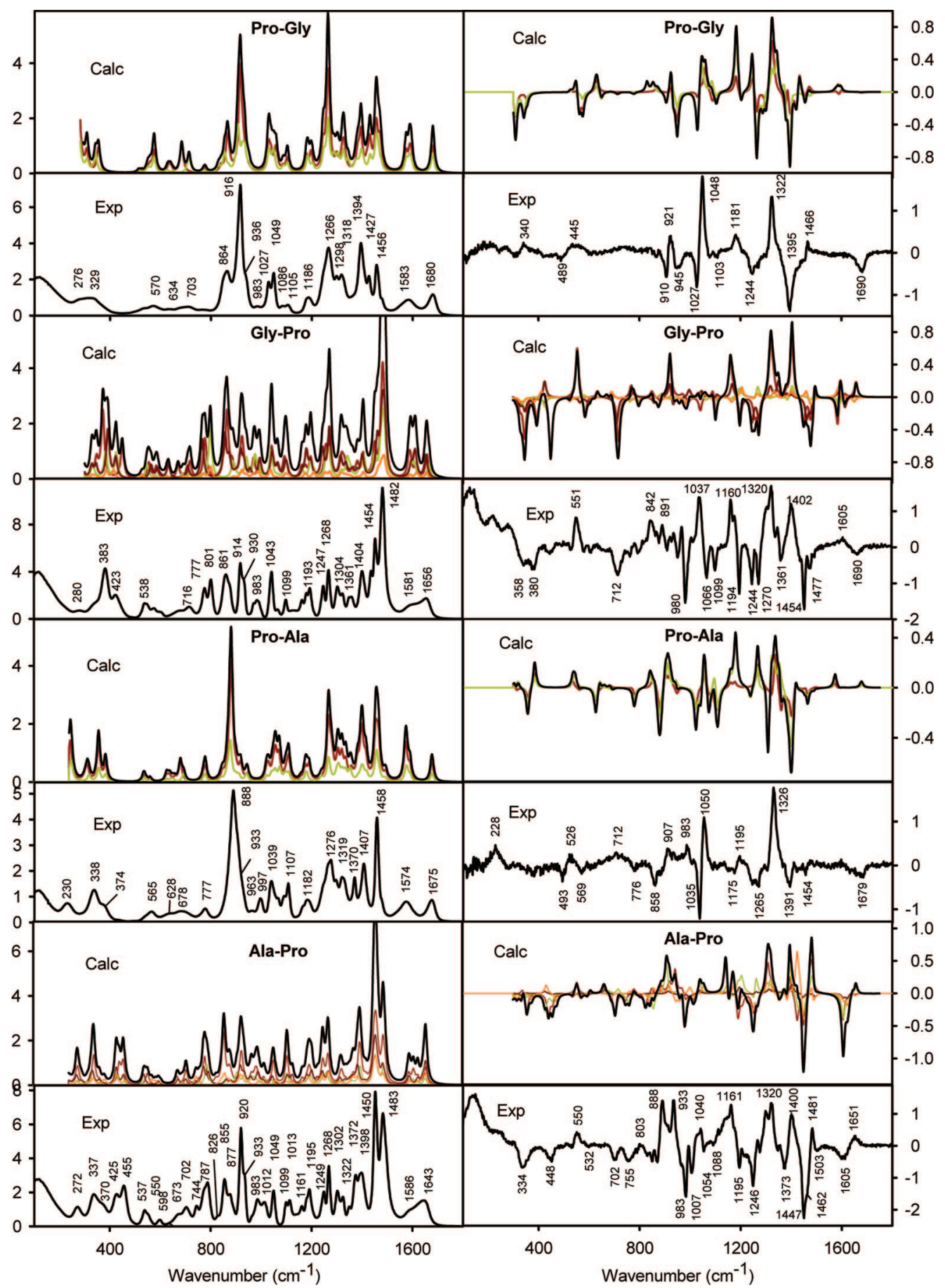

Figure 7. Comparison of the computed and experimental Raman $\left(\left(\mathrm{I}^{\mathrm{R}}+\mathrm{I}^{\mathrm{L}}\right) \times 10^{-9}\right.$, left $)$ and $\mathrm{ROA}\left(\left(\mathrm{I}^{\mathrm{R}}-\mathrm{I}^{\mathrm{L}}\right) \times 10^{-6}\right.$, right $)$ spectra of the four peptides. Calculated contributions of individual conformers are drawn beside the black summary curves.

vibrational scaling based on the manual assignment procedure introduces some variance in the whole process, the correspondence between the calculated vibrations and corresponding Raman bands is rather good, and we estimate that the overall error does not exceed 2-3\% either. The Raman techniques for determination of peptide structures were used several times in the past, ${ }^{10,14,15}$ but to the best of our knowledge this is the first time when the analysis of the ROA intensities reproduces the NMR data and the conformer ratios with such accuracy.

The visibility of the proline conformations in the Raman techniques complements previous studies of this residue by optical spectroscopies and other techniques. As mentioned in the introduction, the IR and VCD techniques have not been used for the monitoring of the peptide sign chain conformation so far, but they could resolve the secondary structure of prolinerich peptides. ${ }^{46-48}$ The ultraviolet techniques are even less local ${ }^{49}$ but also sensitive to polyproline secondary structure. ${ }^{16}$ However, solid-state and computational studies well-recognized the limited flexibility of this residue a long time ago. ${ }^{50-52}$ The approximately equally populated "north" and "south" conformers were predicted on simple models; the detailed conformer distribution, however, varies according to the attached residues. ${ }^{39,53-55}$ By ROA, an equal conformer ratio was predicted for polyproline ${ }^{10}$ and proline zwitterion, ${ }^{13}$ based particularly on the ring deformation (observed at $\sim 850-1000 \mathrm{~cm}^{-1}$ ) and $\mathrm{C}-\mathrm{H}$ bending $\left(\sim 1300-1400 \mathrm{~cm}^{-1}\right)$ proline modes. The present results 


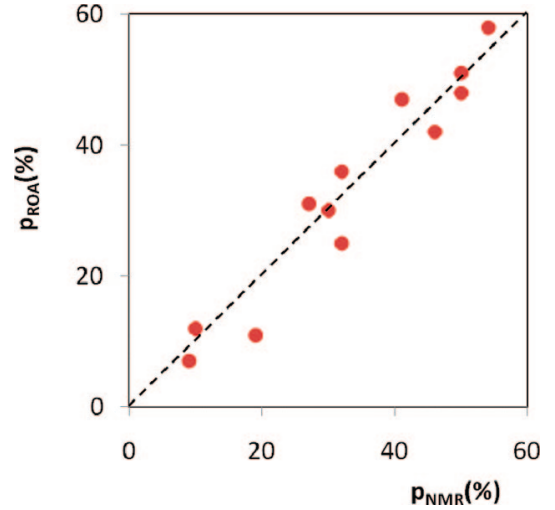

Figure 8. Comparison of the conformer ratios for all the dipeptides obtained from the NMR and the scaled ROA spectra.

are thus in agreement with the previous findings but expand them about the more quantitative information of the conformer ratios. The spectra and the MD simulations also suggest that the limited flexibility of the ring may influence the Raman and ROA shapes. An extraction of the complete molecular potential energy surface from the experimental data, however, goes beyond the goal of the present study.

Although the Raman and ROA technique in the case of the dipeptide provided an exceptional agreement with the NMR analysis and detected conformers invisible to other techniques, particularly VCD, we should also note limitations of the method. The simple decomposition of the ROA spectra has already been used in the past for a more complicated $\beta$-hairpin peptide, ${ }^{19}$ where it provided a less complete information due to the experimental noise and a greater complexity of the spectra. The current manual assignment of all the vibrational normal modes thus might be problematic for bigger molecules, and ultimately the scaling of the computed intensities should be replaced by a more accurate $a b$ initio modeling. Therefore, we view the current study as one of many steps in the establishment of the ROA technique for peptide structural analyses in aqueous solutions.

\section{Conclusions}

We can thus conclude that the simulations provided faithful Raman spectral profiles. The interpretation of the ROA intensities was somewhat hampered by the noise, molecular flexibility, and inaccuracy of the DFT force field, but most of the observed vibrational transitions, intensities, and peak signs could be reproduced. This made it possible to assign the transitions and scale the force constants, which improved the accuracy of the experimental spectra decomposition. Within a few percent the conformer ratios thus obtained agreed with those yielded by the benchmark standard NMR analysis. The conformational behavior of the four dipeptides obtained from the experimental NMR, Raman, and ROA spectra is consistent with the results of the $\mathrm{ab}$ initio and molecular dynamics modeling. As a result, the combined power of ROA spectroscopy and the ab initio interpretation of the data provided yet another reliable means for peptide structural studies.

Acknowledgment. The work was supported by the Czech Science Foundation (grants nos. 203/06/0420, 202/07/0732) and the Grant Agency of the Academy of Sciences (A4005507020). We thank Dr. Radek Pelc for the suggestions to the manuscript.

Supporting Information Available: NMR experimental details and the normal mode vibrational assignment on the basis of the Raman, ROA, and IR spectral intensities. This material is available free of charge via the Internet at http://pubs.acs.org.

\section{References and Notes}

(1) Derewenda, Z. S. Acta Crystallogr., Sect. A: Found. Crystallogr. 2007, 64, 246 6,1630 .

(2) Greenfield, N.; Davidson, B.; Fasman, G. D. Biochemistry 1967,

(3) Timasheff, S. N.; Susi, H.; Townend, R.; Stevens, L.; Gorbunoff, M. J.; Kumosinski, T. F. Application of circular dichroism and infrared spectroscopy to the conformation of proteins in solution. In Conformation of Biopolymers; Ramachandran, G. N., Ed.; Academic Press: London, 1967; Vol. 1; p 173.

(4) Barron, L. D. Nature 2007, 446, 505.

(5) Holzwarth, G.; Hsu, E. C.; Mosher, H. S.; Faulkner, T. R.; Moscowitz, A. J. Am. Chem. Soc. 1974, 96, 251.

(6) Barron, L. D.; Bogaard, M. P.; Buckingham, A. D. J. Am. Chem. Soc. 1973, 95, 603.

(7) Barron, L. D.; Hecht, L.; McColl, I. H.; Blanch, E. W. Mol. Phys. 2004, 102, 731 .

(8) Abdali, S.; Jalkanen, K. J.; Cao, X.; Nafie, L. A.; Bohr, H. Phys. Chem. Chem. Phys. 2004, 6, 2434.

(9) Kapitán, J.; Baumruk, V.; Kopecký, V., Jr.; Bouř, P. J. Phys. Chem. A 2006, 110, 4689.

(10) Kapitán, J.; Baumruk, V.; Kopecký, V., Jr.; Bouř, P. J. Am. Chem. Soc. 2006, 128, 2438.

(11) Haesler, J.; Schindelholz, I.; Riguet, E.; Bochet, C. G.; Hug, W. Nature 2007, 446, 526.

(12) Kapitán, J.; Baumruk, V.; Hulačová, H.; Maloň, P. Vib. Spectrosc. 2006, 42,88

(13) Kapitán, J.; Baumruk, V.; Kopecký, V., Jr.; Pohl, R.; Bouř, P. J. Am. Chem. Soc. 2006, 128, 13451.

(14) Kapitán, J.; Baumruk, V.; Gut, V.; Hlaváček, J.; Dlouhá, H.; Urbanová, M.; Wunsch, E.; Maloň, P. Collect. Czech. Chem. Commun. 2005, $70,403$.

(15) Bouř, P.; Kapitán, J.; Baumruk, V. J. Phys. Chem. A 2001, 105, 6362 .

(16) Dukor, R. K.; Keiderling, T. A. Biospectroscopy 1996, $2,83$.

(17) Parr, R. G.; Yang, W. Density-functional theory of atoms and molecules; Oxford University Press: New York, 1994.

(18) Caricato, M.; Ingrosso, F.; Mennucci, B.; Tomasi, J. J. Chem. Phys. 2005, 122, 154501.

(19) Buděšínský, M.; Šebestík, J.; Bednárová, L.; Baumruk, V.; Šafařík, M.; Bouř, P. J. Org. Chem. 2008, 73, 1481.

(20) Bouř, P.; Baumruk, V.; Hanzliková, J. Collect. Czech. Chem. Commun. 1997, 62, 1384.

(21) van Wijk, J.; Haasnoot, C. A. G.; de Leeuw, F. A. A. M.; Huckriede, B. D.; Westra Hoekzema, A.; Altona, C. PSEUDOROT 6.3; 6.3 ed., Leiden Institute of Chemistry, Leiden University, Leiden, 1999.

(22) Frisch, M. J. ; Trucks, G. W.; Schlegel, H. B.; Scuseria, G. E.; Robb, M. A.; Cheeseman, J. R.; Montgomery, J., J. A.; Vreven, T.; Kudin, K. N., Burant, J. C.; Millam, J. M.; Iyengar, S. S.; Tomasi, J.; Barone, V.; Mennucci, B.; Cossi, M.; Scalmani, G.; Rega, N.; Petersson, G. A.; Nakatsuji, H.; Hada, M.; Ehara, M.; Toyota, K.; Fukuda, R.; Hasegawa, J.; Ishida, M.; Nakajima, T.; Honda, Y.; Kitao, O.; Nakai, H.; Klene, M.; Li, X.; Knox, J. E.; Hratchian, H. P.; Cross, J. B.; Bakken, V.; Adamo, C.; Jaramillo, J.; Gomperts, R.; Stratmann, R. E.; Yazyev, O.; Austin, A. J.; Cammi, R.; Pomelli, C.; Ochterski, J. W.; Ayala, P. Y.; Morokuma, K.; Voth, G. A.; Salvador, P.; Dannenberg, J. J.; Zakrzewski, V. G.; Dapprich, S.; Daniels, A. D.; Strain, M. C.; Farkas, O.; Malick, D. K.; Rabuck, A. D.; Raghavachari, K.; Foresman, J. B.; Ortiz, J. V.; Cui, Q.; Baboul, A. G.; Clifford, S.; Cioslowski, J.; Stefanov, B. B.; Liu, G.; Liashenko, A.; Piskorz, P.; Komaromi, I.; Martin, R. L.; Fox, D. J.; Keith, T.; Al-Laham, M. A.; Peng, C. Y.; Nanayakkara, A.; Challacombe, M.; Gill, P. M. W.; Johnson, B.; Chen, W.; Wong, M. W.; Gonzalez, C.; Pople, J. A. Gaussian 03, Revision C.02, Gaussian, Inc., Wallingford, CT, 2004.

(23) Daněček, P.; Bouř, P. J. Chem. Phys. 2007, 126, 224513.

(24) Becke, A. D. J. Chem. Phys. 1993, 98, 5648.

(25) Klamt, A.; Schuurmann, G. J. Chem. Soc., Perkin Trans. 1993, 2, 799.

(26) Klamt, A. J. Phys. Chem. 1995, 99, 2224

(27) Altona, C.; Sundaralingam, M. J. Am. Chem. Soc. 1972, 94, 8205.

(28) Harvey, S. C.; Prabhakaran, M. J. Am. Chem. Soc. 1986, 108, 6128.

(29) Ponder, J. W. Tinker, Software Tools for Molecular Design; 3.8 ed, Washington University School of Medicine: St. Louis, 2000.

(30) Kamiya, N.; Watanabe, Y. S.; Ono, S.; Higo, J. Chem. Phys. Lett. $\mathbf{2 0 0 5}, 401,312$.

(31) Ponder, J. W.; Case, D. A. Adv. Protein Chem. 2003, 66, 27.

(32) Ren, P.; Ponder, W. J. Phys. Chem. B 2003, 107, 5933.

(33) Barron, L. D. Molecular Light Scattering and Optical Activity; Cambridge University Press: Cambridge, 2004. 
(34) Bouř, P.; Sopková, J.; Bednárová, L.; Maloň, P.; Keiderling, T. A. J. Comput. Chem. 1997, 18, 646.

(35) Bouř, P. J. Comput. Chem. 2001, 22, 426.

(36) Ruud, K.; Helgaker, T.; Bouř, P. J. Phys. Chem. A 2002, 106, 7448.

(37) Polavarapu, P. L. Vib. Spectra Struct. 1984, 13, 103.

(38) Nafie, L. A. Raman Optical Activity. In Modern Nonlinear Optics, Part 3; Evans, M., Kielich, S.; Eds.; Wiley: New York, 1994; Vol. 85, p 105.

(39) Song, I. K.; Kang, Y. K. J. Phys. Chem. B 2005, 109, 16982.

(40) Kang, Y. K.; Park, H. S. J. Mol. Struct. (THEOCHEM) 2005, 718, 17.

(41) Du, C. G.; Zhu, Y. J.; Huang, C. Y.; Gai, F. Proc. Natl. Acad. Sci. U.S.A. 2004, 101, 15915.

(42) Bouř, P.; Michalík, D.; Kapitán, J. J. Chem. Phys. 2005, 122, 144501

(43) Bouř, P.; Buděšínský, M.; Špirko, V.; Kapitán, J.; Šebestík, J.; Sychrovský, V. J. Am. Chem. Soc. 2005, 127, 17079.

(44) Kwac, K.; Lee, K. K.; Han, J.; Oh, K. I.; Cho, M. J. Chem. Phys. 2008, 128, 105106.

(45) Aliev, A. E.; Courtier-Murias, D. J. Phys. Chem. B 2007, 111, 14034
(46) Mastle, W.; Dukor, R. K.; Yoder, G.; Keiderling, T. A. Biopolymers 1995, 36, 623 .

(47) Dukor, R. K.; Keiderling, T. A. Biopolymers 1991, 31, 1747.

(48) Dukor, R. K.; Keiderling, T. A.; Gut, V. Int. J. Pept. Protein Res. 1991, 38, 198

(49) Šebek, J.; Gyurscik, B.; Šebestík, J.; Kejík, Z.; Bernárová, L.; Bouř, P. J. Phys. Chem. A 2007, 111, 2750.

(50) Haasnoot, C. A. G.; DeLeeuw, F. A. A. M.; DeLeeuw, H. P. M.; Altona, C. Biopolymers 1981, 20, 1211.

(51) Sarkar, K.; Young, P. E.; Torchia, D. A. J. Am. Chem. Soc. 1986, $108,6459$.

(52) Kayushina, R. L.; Vainshtein, B. K. Kristallografiya 1965, 10, 833(In Russian). For English translation, see Crystallogr. Rep.

(53) Kang, Y. K.; Choi, H. Y. Biophys. Chem. 2004, 11, 135.

(54) Reichert, D.; Pascui, O.; deAzevedo, E. R.; Bonagamba, T. J.; Arnold, K.; Huster, D. Magn. Reson. Chem. 2004, 42, 276.

(55) Madi, Z. L.; Griesinger, C.; Ernst, R. R. J. Am. Chem. Soc. 1990, 112, 2908.

JP806181Q 